\title{
Peri-operative Outcomes and Survival Following Palliative Gastrectomy for Gastric Cancer: a Systematic Review and Meta-analysis
}

\author{
Joseph Cowling ${ }^{1}$ - Bethany Gorman ${ }^{1}$ • Afrah Riaz ${ }^{1}$ - James R. Bundred ${ }^{1,2}$ - Sivesh K. Kamarajah ${ }^{1,3}$. \\ Richard P. T. Evans ${ }^{1}$ - Pritam Singh ${ }^{4}$ • Ewen A. Griffiths ${ }^{1,3}$ (D)
}

Accepted: 9 September 2020 / Published online: 22 September 2020

(C) The Author(s) 2020

\begin{abstract}
Background Many patients with gastric cancer present with late stage disease. Palliative gastrectomy remains a contentious intervention aiming to debulk tumour and prevent or treat complications such as gastric outlet obstruction, perforation and bleeding.

Methods We conducted a systematic review of the literature for all papers describing palliative resections for gastric cancer and reporting peri-operative or survival outcomes. Data from peri-operative and survival outcomes were meta-analysed using random effects modelling. Survival data from patients undergoing palliative resections, non-resective surgery and palliative chemotherapy were also combined. This study was registered with the PROSPERO database (CRD42019159136).

Results One hundred and twenty-eight papers which included 58,675 patients contributed data. At 1 year, there was a significantly improved survival in patients who underwent palliative gastrectomy when compared to non-resectional surgery and no treatment. At 2 years following treatment, palliative gastrectomy was associated with significantly improved survival compared to chemotherapy only; however, there was no significant improvement in survival compared to patients who underwent nonresectional surgery after 1 year. Palliative resections were associated with higher rates of overall complications versus nonresectional surgery (OR 2.14; 95\% CI, 1.34, 3.46; $p<0.001$ ). However, palliative resections were associated with similar perioperative mortality rates to non-resectional surgery.

Conclusion Palliative gastrectomy is associated with a small improvement in survival at 1 year when compared to non-resectional surgery and chemotherapy. However, at 2 and 3 years following treatment, survival benefits are less clear. Any survival benefits come at the expense of increased major and overall complications.
\end{abstract}

Keywords Stomach neoplasms · Gastrectomy · Survival

Electronic supplementary material The online version of this article (https://doi.org/10.1007/s12029-020-00519-4) contains supplementary material, which is available to authorized users.

Ewen A. Griffiths

ewenagriffiths@gmail.com

1 College of Medical and Dental Sciences, University of Birmingham, Birmingham, UK

2 College of Medical and Dental Sciences, University of Leeds, Leeds, UK

3 Department of Upper GI surgery, Queen Elizabeth Hospital Birmingham, University Hospitals Birmingham NHS FT, Mindelsohn Way, Birmingham B15 2TH, UK

4 Nottingham Oesophago-Gastric Unit, City Hospital, Hucknall Rd, Nottingham NG5 1PB, UK

\section{Introduction}

Primary gastric cancer (GC) is the fifth most common malignancy worldwide and frequently presents at a late and incurable stage [1]. The majority of patients present with either stage 3 or 4 disease and many will have already developed metastasis $[2,3]$ with many patients surviving less than a year after initial diagnosis $[4,5]$. Although the incidence of GC is declining, there are still over 5000 new diagnoses every year in the UK alone and it continues to be the $3^{\text {rd }}$ biggest cause of cancer-related deaths globally [6-8].

Localised GC is often managed with combined resection and chemotherapy owing to a significant body of evidence which demonstrates its survival benefit compared to surgery alone [9-11]. However, advanced GC is generally regarded as 
incurable and resection is often not considered owing to the extent of local tumour invasion and/or the presence of distant metastases [12]. Progressive tumour growth means patients are at risk of tumour-related complications such as gastric outlet obstruction, perforation and bleeding, all of which can lead to reduced quality of life, emergency surgery and ultimately a reduction in life span.

Palliative gastrectomy (PG), comprising of either total, subtotal or distal gastrectomy, is recognised as a treatment for alleviating or preventing these complications, yet its use remains a contentious topic owing to the high-risk nature of the procedure and mixed evidence for its survival benefit in advanced GC [13-15].

Previous evidence has not only demonstrated the absence of any survival benefit from PG but has also shown no improvement in quality of life and an increased number of chemotherapy-associated adverse events $[14,15]$. The REGATTA trial, the only phase III randomised control trial comparing chemotherapy alone and gastrectomy followed by chemotherapy showed no survival benefit and concluded that palliative gastrectomy in patients with metastatic gastric cancer cannot be justified [14]. Some authors have criticised the REGATTA trial for including large numbers of patients requiring total gastrectomy, using oral rather than intra-venous chemotherapy treatment regimens and grouping patients with different sites of metastatic disease together as these factors could affect the interpretation of the results [16].

There is a growing body of non-randomised evidence suggesting that PG not only provides symptomatic relief but can also extend survival [17-20]. With continued uncertainty surrounding the efficacy of PG in advanced GC, the aim of this systematic review and meta-analysis was to analyse both operative and survival outcomes following palliative gastrectomy for advanced primary gastric cancer.

\section{Methods}

\section{Search Strategy}

This study was prospectively registered with the PROSPERO database of systematic reviews (CRD42019159136). A systematic literature search was undertaken by one researcher (SK) using the PubMed, EMBASE and Cochrane Library databases on $25^{\text {th }}$ January 2020. Search terms included 'palliative gastrectomy' or 'palliative total gastrectomy' or 'palliative subtotal gastrectomy' or 'palliative resection' and 'stomach neoplasms' or 'gastric cancer' or 'gastric adenocarcinoma' or 'stomach cancer'. Outcomes including 'post-operative complications', 'mortality', 'disease free survival', 'overall survival' and 'quality of life' were included in the search. Full details of the literature search terms used can be found in Supplementary table 1. The results of the literature search were reported in accordance with the PRISMA guidelines (Fig. 1).

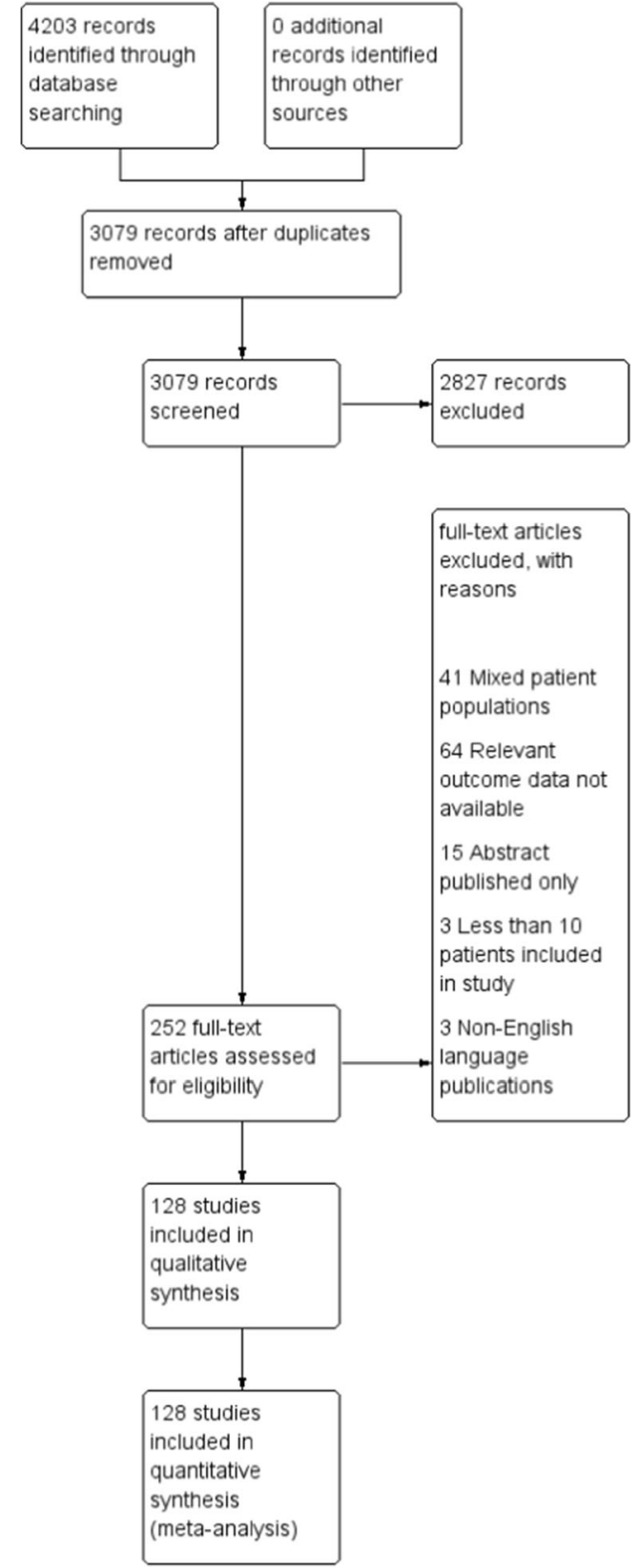

Fig. 1 PRISMA diagram of study inclusion

\section{Inclusion and Exclusion Criteria}

Inclusion criteria were (1) studies reporting outcomes following palliative gastrectomy for primary gastric adenocarcinoma and (2) human studies published in the English language. Exclusion criteria were (1) review articles, case reports, letters, editorials and conference abstracts; (2) studies which exclusively report outcomes for oesophagectomy, oesophagogastrectomy, surgical bypass procedures or curative gastrectomy; (3) studies in which outcomes for palliative gastrectomy were combined with the outcomes of other surgical procedures; (4) gastric cancers other than primary adenocarcinoma. 
All studies generated by the literature search were screened by three independent reviewers for their relevance based on the title, abstract and study type using the above inclusion/ exclusion criteria. All duplications were excluded. In the instance, there was uncertainty about the relevance of a study, the advice was sought of all authors and a final decision was made. Where studies were excluded, the reason for exclusion was verified by a fourth reviewer. For those studies which remained following this initial screening process, full texts were obtained and reviewed in detail by the same three to produce a final list of all included studies.

\section{Study Outcomes}

The primary outcome was overall survival following palliative gastrectomy for primary gastric cancer. Secondary outcomes included overall post-operative complications, major complications, anastomotic leak, pulmonary complications, mortality, overall survival rates (1-, 2-, 3- and 5-year), recurrence-free survival and self-reported quality of life measures.

\section{Data Extraction}

Data was extracted for all included studies by three independent reviewers and any queries were resolved by consensus with all authors. Data was extracted under the following headings: year of publication, study duration, study country, study design, number of study centres, use of comparison groups, overall study sample size, treatment group sample size, stage of gastric cancer, definition of palliative gastrectomy, tumour location, metastasis location, tumour histology, risk factors and chemotherapy use. In addition to extracting data for patients undergoing palliative gastrectomy, where available, data was extracted for other treatment groups under the broad headings of 'curative gastrectomy', 'chemotherapy only', 'non-resectional surgery' and 'no surgery'. This data was collected to enable a comparison to the main intervention of interest, palliative gastrectomy.

\section{Assessment of Methodological Quality}

Three researchers assessed the methodological quality of all included studies using the Newcastle-Ottawa Quality Assessment Scale (NOS) for all comparative cohort studies. This score was omitted in the instance that a study was a non-comparative cohort study, for which the NOS is not valid. The overall grading of each study is given in results supplementary table 1 .

\section{Statistical Analysis}

This systematic review and meta-analysis was conducted in accordance with the recommendations of the Cochrane Library and MOOSE guidelines [15]. For categorical variables, analysis was performed by calculating the odds ratio (OR). For survival analysis, relative risk (RR) statistics were calculated. Random effects modelling, using the DerSimonian-Laird method was used for the meta-analysis of outcomes. Heterogeneity between studies was assessed using the $I_{2}$ value in order to determine the degree of variation not attributable to chance alone. $I_{2}$ values were considered to represent low, moderate and high degrees of heterogeneity where values were $<25 \%, 25-75 \%$, and $>75 \%$, respectively. Assessment of small study bias was carried out by visual assessment of funnel plots and egger regressions. Statistical significance was considered when $p<0.05$. Statistical analyses were performed using $\mathrm{R}$ statistical software ( $\mathrm{R}$ version 3.5.2, $\mathrm{R}$ Foundation for Statistical Computing, Vienna, Austria).

\section{Results}

\section{Study Characteristics}

The literature search identified 128 studies reported according to the PRISMA guidelines as shown in Fig. 1. Studies identified were from North America $(n=14)$, South America $(n=7)$, Australasia $(n=72)$ and Europe $(n=35)$. The majority of studies were retrospective cohort studies $(n=123)$, with the remainder prospective cohort studies $(n=3)$ and RCTs $(n=2)$. Sixty-one studies identified were reported after 2010, the remaining 67 studies before 2010. Of the studies that reported on either clinical or pathological tumour stage, 41 of 91 studies consisted entirely of patients with $T$ stage 4 disease. On average across 91 studies reporting the percentage of patients with $\mathrm{T}$ stage 4 disease, $68.6 \%$ of patients had $\mathrm{T}$ stage 4 disease. There was considerable variation in whether resections were defined as palliative due to the advanced $\mathrm{T}$ stage of the primary tumour or due to distant metastasis (Table 1). Across studies containing a proportion of patients with metastatic disease, 9 studies of 93 included only patients with lymph node metastases, whilst 84 included patients with a mixture of metastases sites. Of these, 41 of 84 studies included patients with liver metastases, 14 studies included patients with lung metastases and 40 included patients with peritoneal metastases.

\section{Reporting Standards and Methodological Quality}

Study quality was assessed using NOS, median 8 , ranging between 5 and 9 , indicating generally high quality cohort studies (Supplementary Table 1). A summary of studies reporting the impact of intervention type on morbidity and mortality is provided in Table 2 . 


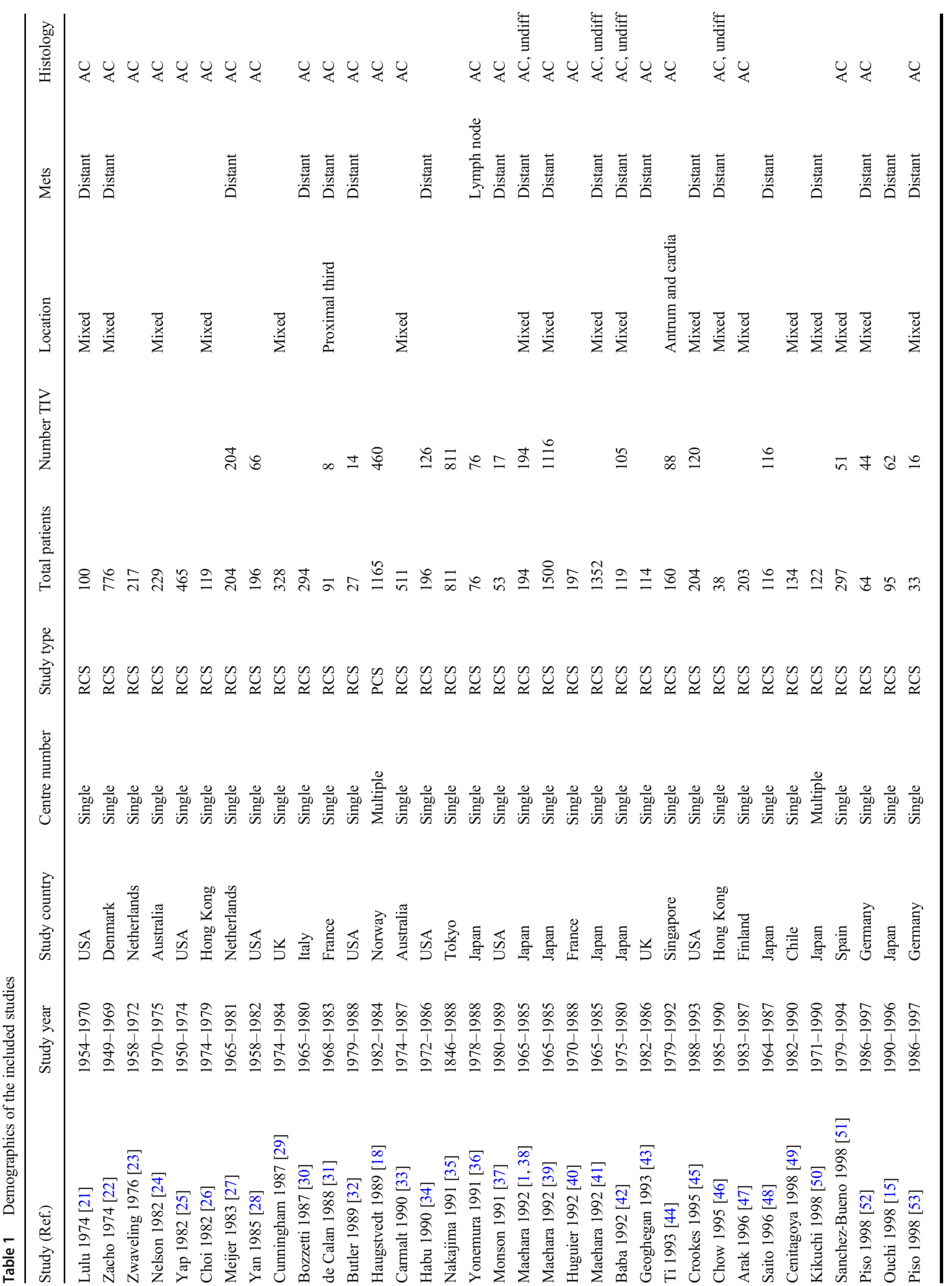




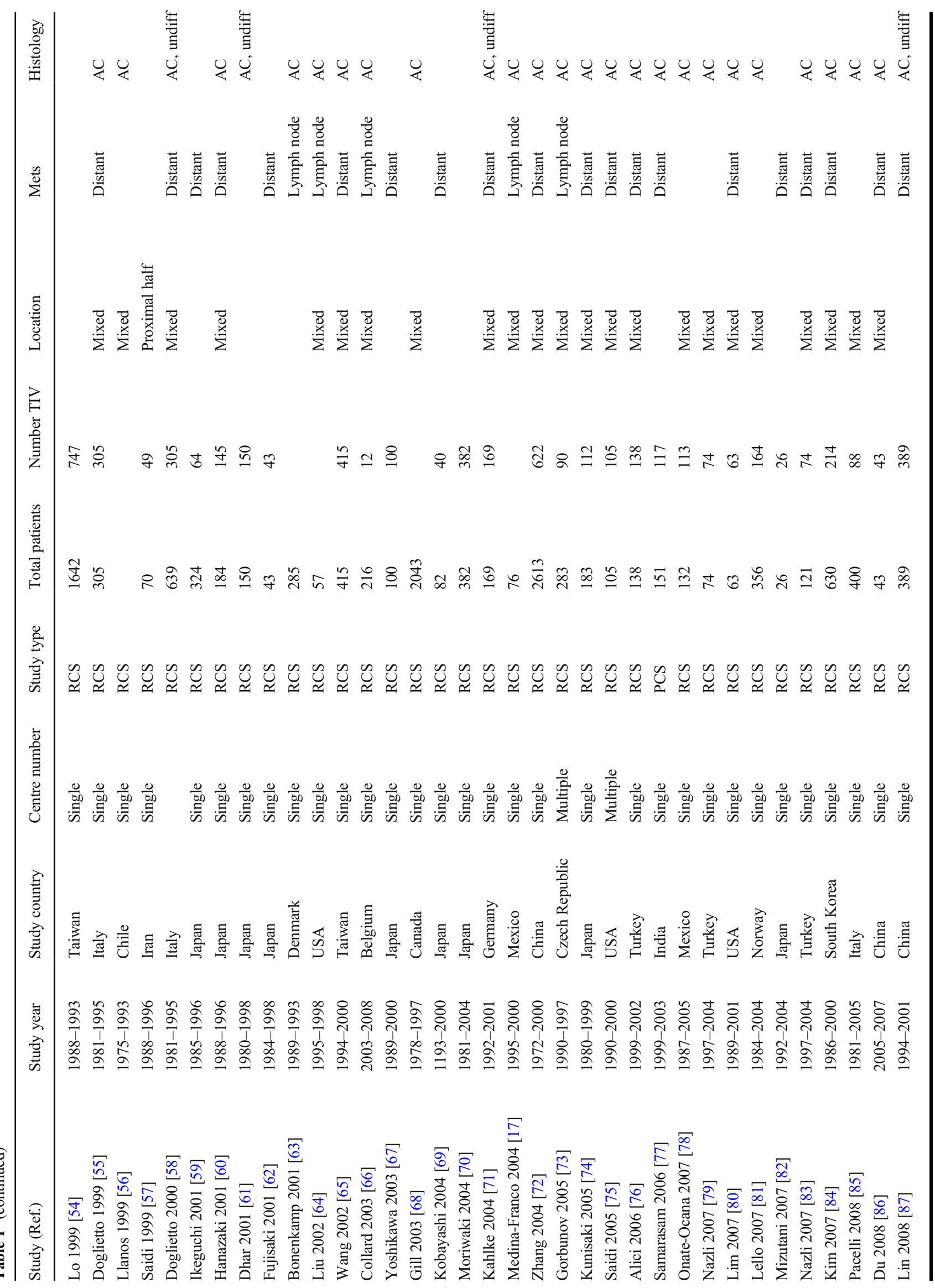




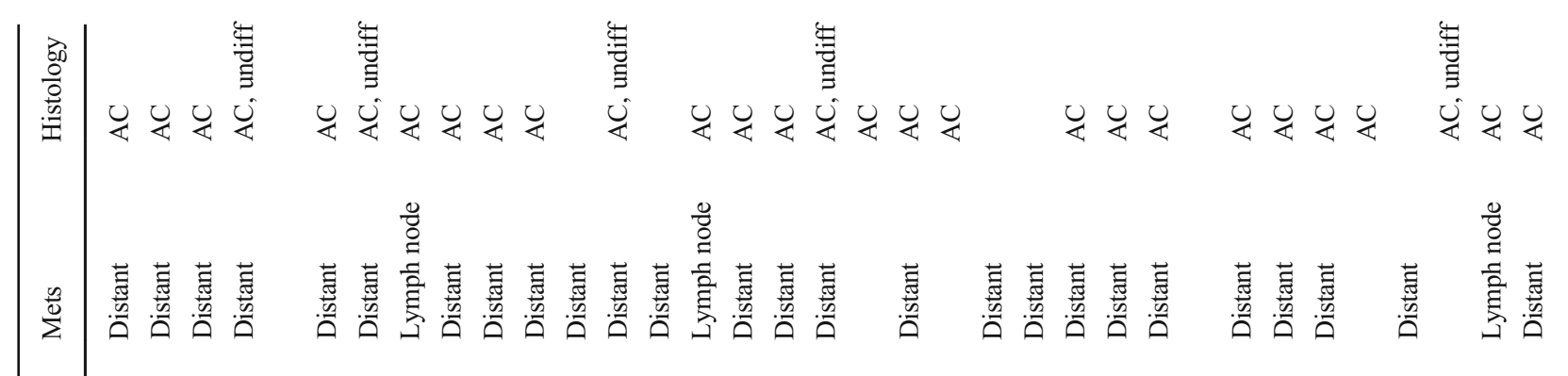

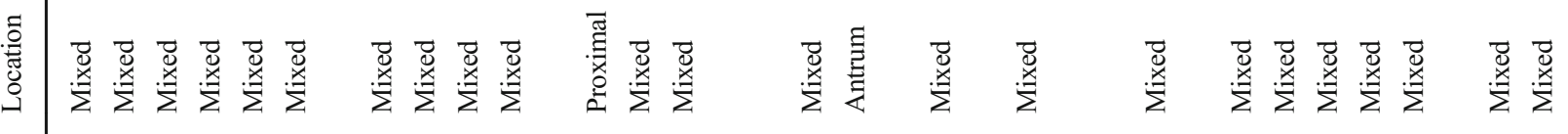

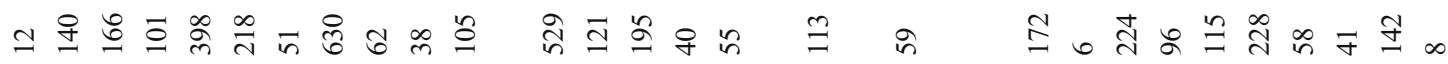

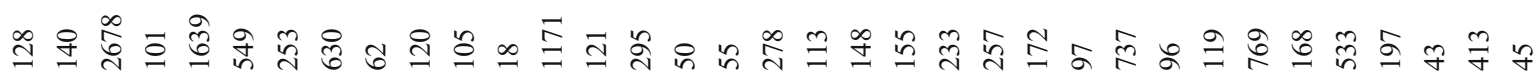

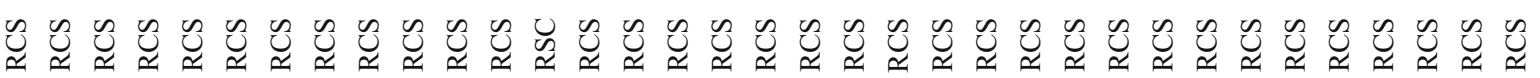

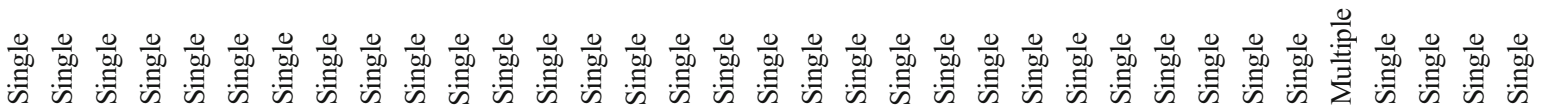

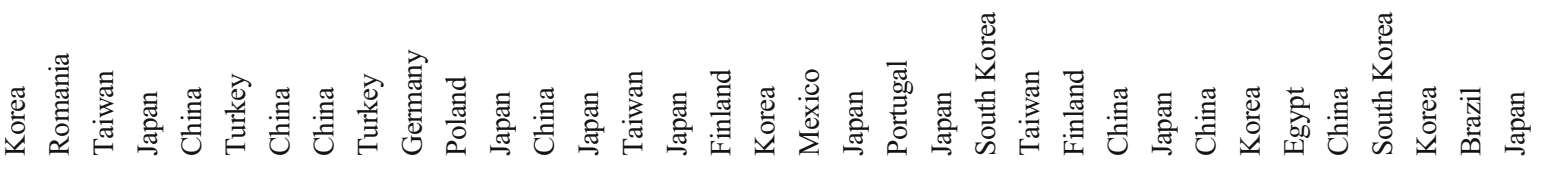

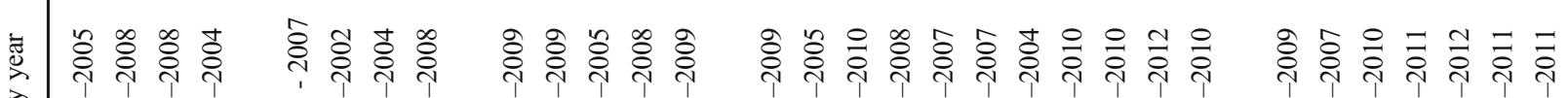

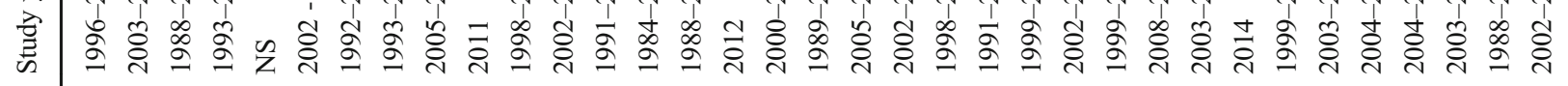

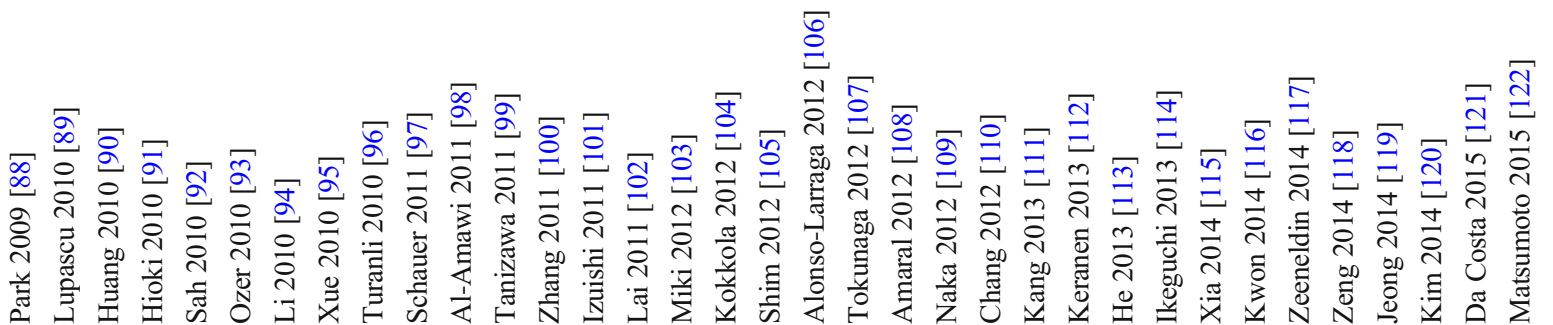




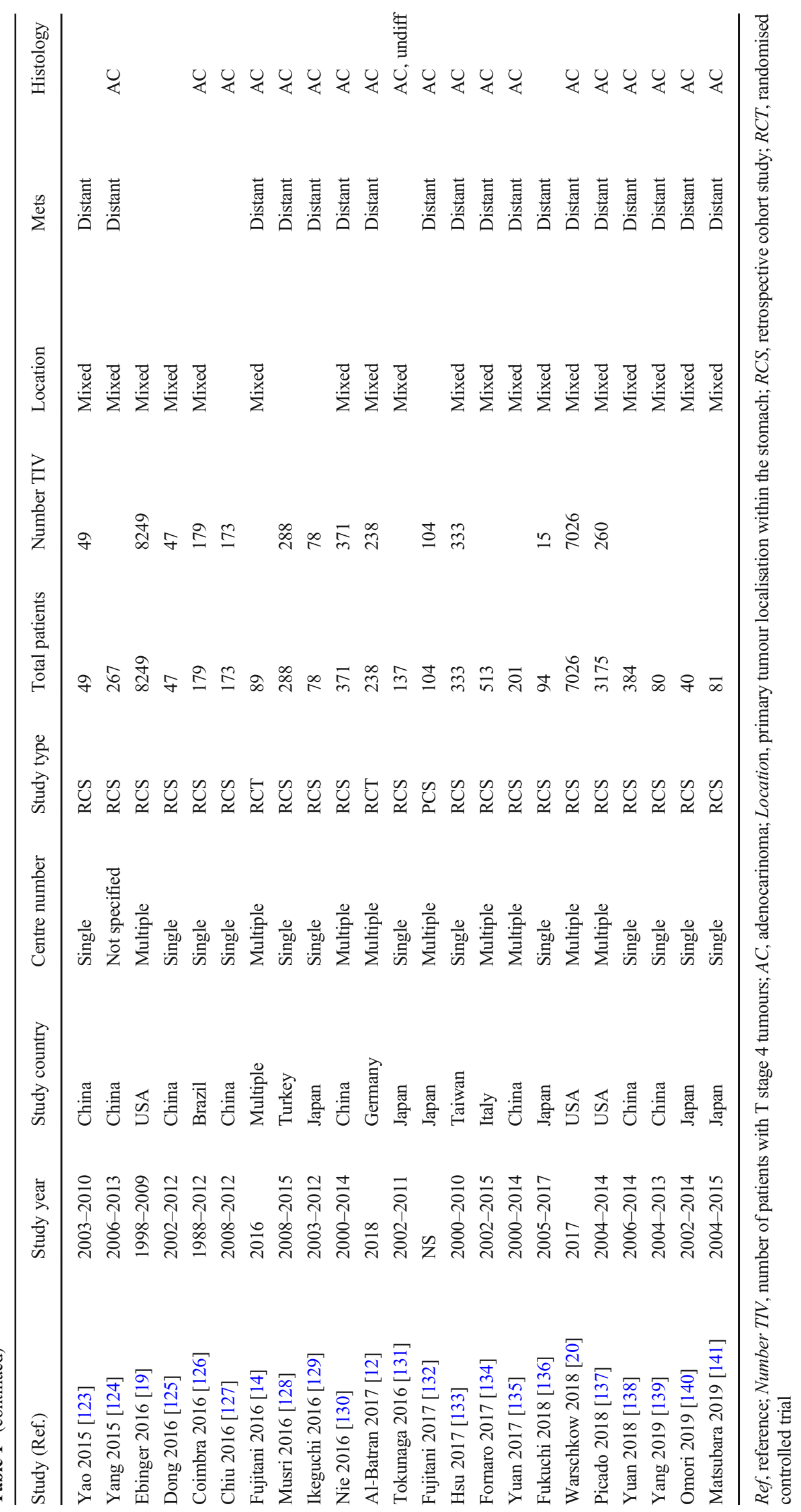


Table 2 Differences in short post-operative outcomes comparing non-resectional procedures and curative intent resections to palliative surgery

\begin{tabular}{|c|c|c|c|c|}
\hline & $N$ & Odds ratio & Confidence intervals & $p$ value \\
\hline \multicolumn{5}{|c|}{ Palliative gastrectomy versus non-resectional procedures } \\
\hline Overall complications & 15 & 2.15 & $1.34-3.46$ & $<0.001$ \\
\hline Major complications & 2 & 3.41 & $1.42-8.20$ & 0.01 \\
\hline Anastomotic leak & 11 & 2.35 & $1.14-4.84$ & 0.02 \\
\hline Peri-operative mortality & 19 & 1.10 & $0.73-1.66$ & 0.66 \\
\hline \multicolumn{5}{|c|}{ Palliative gastrectomy versus curative intent resection } \\
\hline Overall complications & 17 & 1.46 & $1.18-1.79$ & $<0.001$ \\
\hline Major complications & 9 & 1.51 & $0.87-2.62$ & 0.12 \\
\hline Anastomotic leak & 13 & 1.01 & $0.56-1.85$ & 0.98 \\
\hline Peri-operative mortality & 29 & 1.89 & $1.34-2.65$ & $<0.001$ \\
\hline \multicolumn{5}{|c|}{ Palliative gastrectomy versus non-resectional procedures (published post-2010) } \\
\hline Overall complications & 8 & 1.493 & $1.043-2.138$ & $<0.001$ \\
\hline Major complications & 2 & 3.41 & $1.42-8.20$ & 0.01 \\
\hline Anastomotic leak & 6 & 2.311 & $0.653-8.175$ & 0.194 \\
\hline Peri-operative mortality & 3 & 0.361 & $0.082-1.59$ & 0.178 \\
\hline \multicolumn{5}{|c|}{ Palliative gastrectomy versus curative intent resection (published post-2010) } \\
\hline Overall complications & 6 & 1.536 & $1.013-2.328$ & 0.043 \\
\hline Major complications & 2 & 1.294 & $0.392-4.272$ & 0.672 \\
\hline Anastomotic leak & 5 & 0.789 & $0.212-2.915$ & 0.724 \\
\hline Peri-operative mortality & 11 & 1.397 & $0.696-2.821$ & 0.348 \\
\hline
\end{tabular}

\section{Peri-operative Outcomes}

\section{Overall Complications}

Fifteen studies reported data on overall complications comparing patients undergoing palliative surgery compared to non-resectional procedures. Palliative gastrectomy was associated with an increase in overall complications compared to non-resectional surgery (OR 2.14; 95\% CI, 1.34, 3.46; $p<0.001 ; I_{2}=46 \%$ ) (Table 3). Egger regression analysis suggested a significant publication bias $(p=0.004)$, with a Duval and tweedie imputed OR and 95\% CI, 1.43 (0.81, 2.54). Seventeen studies reported data on overall complications comparing palliative surgery to curative intent surgery. Palliative surgery was associated with an increase in overall complications compared to curative surgery (OR 1.46; 95\% CI, 1.18, 1.79; $p<0.001 ; I_{2}=47 \%$ ). No significant publication bias was identified through egger regression testing $(p=0.871)$.

\section{Major Complications}

Two studies reported data on major complications comparing patients undergoing palliative gastrectomy compared to non-resectional procedures. Palliative surgery was associated with an increase in major complications compared to non-resectional surgery (OR $3.41 ; 95 \% \mathrm{CI}$, $1.42,8.20 ; p<0.001 ; I_{2}=0 \%$ ) (Table 3). Insufficient data were available for egger regression testing. Nine studies reported data on overall complications comparing palliative surgery to curative intent surgery. Palliative surgery was associated with an increase in major complications compared to curative surgery (OR $1.51 ; 95 \%$ CI, $\left.0.87,2.52 ; p=0.12 ; I_{2}=84 \%\right)$. No significant publication bias was identified through egger regression testing $(p=0.702)$.

\section{Anastomotic Leak}

Eleven studies reported data on anastomotic leak comparing patients undergoing palliative surgery compared to non-resectional procedures. Palliative Surgery was associated with an increase in anastomotic leak compared to non-resectional surgery (OR 2.35; 95\% CI, 1.14, 4.84; $p=0.02 ; I_{2}=0 \%$ ) (Table 3 ). Egger regression analysis suggested an insignificant publication bias $(p=$ 0.654). Thirteen studies reported data on anastomotic leak comparing palliative surgery to curative intent surgery. Palliative surgery was associated with similar rates of anastomotic leak compared to curative surgery (OR $1.01 ; 95 \%$ CI, 0.56, 1.42; $p=0.98 ; I_{2}=71 \%$. No significant publication bias was identified through egger regression testing $(p=0.945)$. 
Table 3 Relative risk and 95\% confidence intervals of different treatment strategies versus palliative gastrectomy at 1-, 2-, 3 and 5-year survival

\begin{tabular}{|c|c|c|c|c|c|}
\hline & $N$ & $\mathrm{RR}$ & $95 \% \mathrm{CI}$ & $p$ & $I_{2}$ \\
\hline \multicolumn{6}{|l|}{ 1-year survival } \\
\hline Palliative gastrectomy vs. chemotherapy only & 5 & 0.734 & $0.559-0.963$ & 0.0256 & $81 \%$ \\
\hline Palliative gastrectomy vs. non-resectional procedures & 7 & 0.421 & $0.197-0.909$ & 0.0435 & $82 \%$ \\
\hline Palliative gastrectomy vs. no intervention & 8 & 0.381 & $0.176-0.827$ & 0.0147 & $91 \%$ \\
\hline \multicolumn{6}{|l|}{ 2-year survival } \\
\hline Palliative gastrectomy vs. chemotherapy only & 6 & 0.508 & $0.352-0.744$ & 0.040 & $81 \%$ \\
\hline Palliative gastrectomy vs. non-resectional procedures & 5 & 0.432 & $0.150-1.194$ & 0.4434 & $85 \%$ \\
\hline Palliative gastrectomy vs. no intervention & 6 & 0.277 & $0.239-0.326$ & $<0.001$ & $0 \%$ \\
\hline \multicolumn{6}{|l|}{ 3-year survival } \\
\hline Palliative gastrectomy vs. chemotherapy only & 4 & 0.578 & $0.298-1.07$ & 0.2285 & $70 \%$ \\
\hline Palliative gastrectomy vs. non-resectional procedures & 1 & - & - & - & - \\
\hline Palliative gastrectomy vs. no intervention & 3 & 0.225 & $0.181-0.284$ & $<0.001$ & $0 \%$ \\
\hline \multicolumn{6}{|l|}{ Papers published post-2010 subgroup } \\
\hline \multicolumn{6}{|l|}{ 1-year survival } \\
\hline Palliative gastrectomy vs. chemotherapy only & 5 & 0.734 & $0.559-0.963$ & 0.0256 & $81 \%$ \\
\hline Palliative gastrectomy vs. non-resectional procedures & 1 & - & - & - & - \\
\hline Palliative gastrectomy vs. no intervention & 1 & - & - & - & - \\
\hline \multicolumn{6}{|l|}{ 2-year survival } \\
\hline Palliative gastrectomy vs. chemotherapy only & 6 & 0.508 & $0.347-0.742$ & $<0.001$ & $81 \%$ \\
\hline Palliative gastrectomy vs. non-resectional procedures & 1 & - & - & - & - \\
\hline Palliative gastrectomy vs. no intervention & 2 & 1.101 & $0.407-2.974$ & 0.562 & $0 \%$ \\
\hline \multicolumn{6}{|l|}{ 3-year survival } \\
\hline Palliative gastrectomy vs. chemotherapy only & 5 & 0.567 & $0.299-1.074$ & 0.0816 & $54 \%$ \\
\hline Palliative gastrectomy vs. non-resectional procedures & 1 & - & - & - & - \\
\hline Palliative gastrectomy vs. no intervention & 1 & - & - & - & - \\
\hline
\end{tabular}

\section{Early Post-operative Mortality}

Nineeen studies reported data on early post-operative mortality comparing patients undergoing palliative surgery compared to non-resectional procedures. Palliative surgery was not associated with a significant increase in early postoperative mortality compared to non-resectional surgery (OR $1.10 ; 95 \%$ CI, 0.73, 1.66; $p=0.66 ; I_{2}=21 \%$ ). Egger regression analysis suggested an insignificant publication bias $(p=$ $0.495)$. Twenty-nine studies reported data on early postoperative mortality comparing palliative surgery to curative intent surgery. Palliative surgery was associated with an increase in early post-operative mortality compared to curative surgery (OR 1.89; 95\% CI, 1.34, 2.65; $p=0.98 ; I_{2}=43 \%$ ). No significant publication bias was identified through egger regression testing $(p=0.673)$.

\section{Long-term Survival}

\section{1-Year Survival}

Twenty studies reported numbers surviving at 1 year following palliative surgery, non-resectional surgery, chemotherapy or no treatment. Palliative surgery was associated with an improved 1-year survival compared to non-resectional surgery (RR 0.421, 0.197-0.909; $p=0.044$ ), chemotherapy (RR $0.734,0.575-0.963 ; p=0.026$ ) and no treatment (OR 0.381 , $0.176-0.827 ; p=0.015$ ) (Table 4).

\section{2-Year Survival}

Seventeen studies reported numbers surviving at 2 years following palliative surgery, non-resectional surgery, chemotherapy or no treatment. Palliative surgery was associated with an improved 2-year survival compared to non-resectional surgery (RR 0.432, 0.150-1.194; $p=0.44$ ), chemotherapy (RR 0.508, $0.352-0.744 ; p=0.04$ ) and no treatment (RR 0.277, 0.239$0.326 ; p<0.001)$ (Table 4).

\section{3-Year Survival}

Eight studies reported numbers surviving at 3 years following palliative surgery, non-resectional surgery, chemotherapy or no treatment. Palliative surgery was associated with an improved 3-year survival compared to chemotherapy (RR 
Table 4 Relative risk and 95\% confidence intervals of different treatment strategies versus palliative gastrectomy at 1-, 2-, 3 - and 5-year survival

\begin{tabular}{|c|c|c|c|c|c|}
\hline & $N$ & $\mathrm{RR}$ & $95 \% \mathrm{CI}$ & $p$ & $I_{2}$ \\
\hline \multicolumn{6}{|l|}{ 1-year survival } \\
\hline Palliative gastrectomy vs. chemotherapy only & 5 & 0.734 & $0.559-0.963$ & 0.0256 & $81 \%$ \\
\hline Palliative gastrectomy vs. non-resectional procedures & 7 & 0.421 & $0.197-0.909$ & 0.0435 & $82 \%$ \\
\hline Palliative gastrectomy vs. no intervention & 8 & 0.381 & $0.176-0.827$ & 0.0147 & $91 \%$ \\
\hline \multicolumn{6}{|l|}{ 2-year survival } \\
\hline Palliative gastrectomy vs. chemotherapy only & 6 & 0.508 & $0.252-0.997$ & 0.045 & $81 \%$ \\
\hline Palliative gastrectomy vs. non-resectional procedures & 5 & 0.442 & $0.071-2.697$ & 0.4434 & $85 \%$ \\
\hline Palliative gastrectomy vs. no intervention & 6 & 0.277 & $0.239-0.326$ & $<0.001$ & $0 \%$ \\
\hline \multicolumn{6}{|l|}{ 3-year survival } \\
\hline Palliative gastrectomy vs. chemotherapy only & 4 & 0.578 & $0.298-1.12$ & 0.2285 & $70 \%$ \\
\hline Palliative gastrectomy vs. non-resectional procedures & 1 & - & - & - & - \\
\hline Palliative gastrectomy vs. no intervention & 3 & 0.225 & $0.181-0.284$ & $<0.001$ & $0 \%$ \\
\hline \multicolumn{6}{|l|}{ Papers published post-2010 subgroup } \\
\hline \multicolumn{6}{|l|}{ 1-year survival } \\
\hline Palliative gastrectomy vs. chemotherapy only & 5 & 0.734 & $0.559-0.963$ & 0.0256 & $81 \%$ \\
\hline Palliative gastrectomy vs. non-resectional procedures & 1 & - & - & - & - \\
\hline Palliative gastrectomy vs. no intervention & 1 & - & - & - & - \\
\hline \multicolumn{6}{|l|}{ 2-year survival } \\
\hline Palliative gastrectomy vs. chemotherapy only & 6 & 0.508 & $0.347-0.742$ & $<0.001$ & $81 \%$ \\
\hline Palliative gastrectomy vs. non-resectional procedures & 1 & - & - & - & - \\
\hline Palliative gastrectomy vs. no intervention & 2 & 1.101 & $0.407-2.974$ & 0.562 & $0 \%$ \\
\hline \multicolumn{6}{|l|}{ 3-year survival } \\
\hline Palliative gastrectomy vs. chemotherapy only & 5 & 0.567 & $0.299-1.074$ & 0.0816 & $54 \%$ \\
\hline Palliative gastrectomy vs. non-resectional procedures & 1 & - & - & - & - \\
\hline Palliative gastrectomy vs. no Intervention & 1 & - & - & - & - \\
\hline
\end{tabular}

$0.578,0.298-1.12 ; p=0.23)$ and no treatment (RR 0.225, $0.181-0.284 ; p<0.001$ ) (Table 4).

\section{Discussion}

This review identifies an association between palliative gastrectomy and improved overall survival for patients with gastric cancer treated palliatively, compared to chemotherapy, non-resectional surgery and no treatment, at 1 year. After 1 year, palliative gastrectomy was not associated with a survival benefit over non-resectional surgery. Significantly, palliative gastrectomy was associated with increased morbidity compared to non-resectional surgery; however, this was not simultaneously associated with increased peri-operative mortality.

This study encompasses all relevant trials up until January 2020. Surgical techniques and oncological therapies have improved markedly during the inclusion period which extends from 1974 to 2018. Potential improvements in clinical practice may have enabled improved patient selection for gastrectomy. Improvement in surgical and oncological techniques concurrently with improved patient selection aims to optimise survival for those fit for some form of resection. Current patient selection uses criteria such as patient performance status, co-morbidity, extent of disease and importantly patient choice. The extent to which biology of the disease dictates outcome is poorly understood, however, with ongoing research into the genetics of gastric cancer [142, 143] with the potential to further refine selection in the future, further optimising outcomes [144, 145].

The study, although comprehensive, including 128 papers which included 58,675 patients did include studies from over 40 years, some of which may have limited clinical relevance; however, subgroup analyses of papers published in the last decade did not show significantly different results. The study did not incorporate outcomes for palliative gastrectomy which were combined with the outcomes of other surgical procedures such as cytoreductive surgery (CRS) which together may improve survival for those who would otherwise receive palliative oncological therapies. The precise reason for palliative surgery and the extent of disease burden was heterogeneous throughout the studies identified and the lack of current clinical guidelines or consensus on this topic makes this extremely difficult to standardise. Very few studies reported on health-related quality of life measures, following palliative gastrectomy. In an era where health research aims to re- 
focus on patient perceived benefits, any measured improvement in health-related quality of life could be considered more important than small improvements in quantity of life with comorbid surgical procedures.

Challenges remain as how to determine treatment choice based on the extent of local disease and whether patients with T4b disease should receive surgery. There is significant variation in unit practice as to whether patients receive a multivisceral resection (MVR) or palliative surgery. MVR is associated with a significant morbidity and mortality in excess of the accepted risks of gastrectomy [146]. This is particularly evident when distal pancreatectomy is required to achieve an R0 resection [147]. Despite this, performing an MVR to achieve an $\mathrm{R} 0$ resection does provide a survival advantage and should be a potential treatment option in patients deemed sufficiently fit for surgery of this magnitude [148].

The role of surgery in metastatic gastric cancer continues to evolve as treatment options mirror treatment advances in other malignancies. Hepatectomy for colorectal liver metastasis has been show to improve survival compared to other palliative treatment options [149]. There is now evidence to demonstrate that hepatectomy for gastric cancer metastases is associated with longer median overall survival than palliative treatments for selected patients $[150,151]$. Peritoneal carcinomatosis is predominantly treated with systemic chemotherapy; however, cytoreductive surgery and heated intraperitoneal chemotherapy (CRS and HIPEC) have been shown in highly selected patients to provide a survival advantage [152, 153]. Pressurised intraperitoneal aerosol chemotherapy has also been demonstrated to be safe and provides beneficial antitumour activity in patients with gastric cancer peritoneal carcinomatosis [154]. Although this systematic review and meta-analysis does not specifically examine the potential beneficial adjuncts to gastrectomy, it is important to identify that achieving a survival advantage with surgery may require a multi-modal approach.

It is currently not clear to what extent oncological therapies could be used in concordance with surgery and whether patients undergoing palliative resection should be offered neoadjuvant and adjuvant chemotherapy, as standard, particularly in an era where FLOT (5-fluorouracil, folinic acid, oxaliplatin, docetaxel) is becoming the gold standard of oncological treatment for patients with oesophago-gastric cancer. The REGATTA trial randomised patients to gastrectomy with D1 lymphadenectomy without any resection of metastatic lesions and adjuvant chemotherapy or chemotherapy alone and found no significant difference in overall survival [14]. Subsequently, there has been a trend away from the use of surgery in improving survival in patients who are known to have metastatic gastric cancer [155].

The AIO-FLOT 3 trial compared patients with limited metastatic disease who benefited from neoadjuvant FLOT to patients with resectable disease and to patients with extensive metastatic disease [12]. The trial identified that patients with limited metastatic disease who received neoadjuvant chemotherapy and proceeded to surgery showed a favourable survival when compared to expected survival for patients with metastatic disease. The trial did not determine the additional benefit of surgery in patients with limited metastatic disease who showed a good response to chemotherapy. Improvements in chemotherapy in conjunction with improving surgical techniques inclusive of a D2 gastrectomy and metastatectomy may provide improved survival for patients who previously may have been palliated.

Oncological therapies continue to develop and immunotherapy is increasingly playing a role in gastric cancer as is evident with HER2 positive tumours and the use of trastuzumab [156]. Further studies continue into the importance of HER-2 blockade in the form of trastuzamab and pertuzamab in conjunction with FLOT in the Petrarca Trial which is yet to report [157]. Increasingly immunotherapy trials continue to examine the benefits of PD1/PD-L1 and CTLA4 blockade and will likely be incorporated into the treatment pathways of advanced gastric cancer [158-160].

\section{Conclusions}

Palliative gastrectomy is associated with significant morbidity over and above non-resectional palliative surgery and gastrectomy for curative intent. Palliative gastrectomy may offer an early survival advantage compared to oncological therapies given in isolation; however, this does not extend beyond a couple of years and may well result from patient selection biases. Further research into the biology of gastric cancer and improved techniques for patient selection are required to improve overall survival for patients with palliative gastric cancer.

\section{Compliance with Ethical Standards}

Conflict of Interest The authors declare that they have no conflicts of interest.

Open Access This article is licensed under a Creative Commons Attribution 4.0 International License, which permits use, sharing, adaptation, distribution and reproduction in any medium or format, as long as you give appropriate credit to the original author(s) and the source, provide a link to the Creative Commons licence, and indicate if changes were made. The images or other third party material in this article are included in the article's Creative Commons licence, unless indicated otherwise in a credit line to the material. If material is not included in the article's Creative Commons licence and your intended use is not permitted by statutory regulation or exceeds the permitted use, you will need to obtain permission directly from the copyright holder. To view a copy of this licence, visit http://creativecommons.org/licenses/by/4.0/. 


\section{References}

1. Oh JK, Weiderpass E. Infection and cancer: global distribution and burden of diseases. Ann Glob Health. 2014;80(5):384-92.

2. Wanebo HJ, Kennedy BJ, Chmiel J, Steele G Jr, Winchester D, Osteen R. Cancer of the stomach. A patient care study by the American College of Surgeons. Ann Surg. 1993;218(5):583-92.

3. Izuishi K, Mori H. Recent strategies for treating stage IV gastric cancer: roles of palliative gastrectomy, chemotherapy, and radiotherapy. J Gastrointestin Liver Dis. 2016;25(1):87-94.

4. Reim D, Loos M, Vogl F, Novotny A, Schuster T, Langer R, et al. Prognostic implications of the seventh edition of the international union against cancer classification for patients with gastric cancer: the Western experience of patients treated in a single-center European institution. J Clin Oncol. 2013;31(2):263-71.

5. Service NCRaA. Stage Breakdown by CCG 2014. London: NCRAS; 2014.

6. Ferlay J, Soerjomataram I, Dikshit R, Eser S, Mathers C, Rebelo $\mathrm{M}$, et al. Cancer incidence and mortality worldwide: sources, methods and major patterns in GLOBOCAN 2012. Int J Cancer. 2015;136(5):E359-86.

7. NCRAS. National cancer research and analysis service: Public Health England. http://www.ncras.nhs.uk 2016

8. Global Burden of Disease Cancer C, Fitzmaurice C, Allen C, Barber RM, Barregard L, Bhutta ZA, et al. Global, regional, and national cancer incidence, mortality, years of life lost, years lived with disability, and disability-adjusted life-years for 32 cancer groups, 1990 to 2015: a systematic analysis for the global burden of disease study. JAMA Oncol. 2017;3(4):524-48.

9. Cunningham D, Allum WH, Stenning SP, Thompson JN, Van de Velde CJ, Nicolson M, et al. Perioperative chemotherapy versus surgery alone for resectable gastroesophageal cancer. N Engl J Med. 2006;355(1):11-20.

10. Ahn HS, Jeong SH, Son YG, Lee HJ, Im SA, Bang YJ, et al. Effect of neoadjuvant chemotherapy on postoperative morbidity and mortality in patients with locally advanced gastric cancer. $\mathrm{Br} \mathbf{J}$ Surg. 2014;101(12):1560-5.

11. Grau JJ, Martin M, Fuster J, Pera M, Garcia-Valdecasas JC, Bombi JA, et al. Impact of adjuvant chemotherapy in the longterm outcome of patients with resected gastric cancer. J Surg Oncol. 2003;82(4):234-40.

12. Al-Batran SE, Homann N, Pauligk C, Illerhaus G, Martens UM, Stoehlmacher J, et al. Effect of neoadjuvant chemotherapy followed by surgical resection on survival in patients with limited metastatic gastric or gastroesophageal junction cancer: the AIOFLOT3 trial. JAMA Oncol. 2017;3(9):1237-44.

13. Sarela AI, Yelluri S. Leeds Upper Gastrointestinal Cancer Multidisciplinary T. Gastric adenocarcinoma with distant metastasis: is gastrectomy necessary? Arch Surg. 2007;142(2):143-9 discussion 9.

14. Fujitani K, Yang HK, Mizusawa J, Kim YW, Terashima M, Han SU, et al. Gastrectomy plus chemotherapy versus chemotherapy alone for advanced gastric cancer with a single non-curable factor (REGATTA): a phase 3, randomised controlled trial. Lancet Oncol. 2016;17(3):309-18.

15. Ouchi K, Sugawara T, Ono H, Fujiya T, Kamiyama Y, Kakugawa $\mathrm{Y}$, et al. Therapeutic significance of palliative operations for gastric cancer for survival and quality of life. J Surg Oncol. 1998;69(1):41-4.

16. Oh S-Y, Lee H-J. REGATTA trial: its achievement and issues unsolved. Transl Cancer Res. 2017;6(S6):S976-S978. https:/ doi.org/10.21037/13960

17. Medina-Franco H, Contreras-Saldivar A, Ramos-De La Medina A, Palacios-Sanchez P, Cortes-Gonzalez R, Ugarte JA. Surgery for stage IV gastric cancer. Am J Surg. 2004;187(4):543-6.
18. Haugstvedt T, Viste A, Eide GE, Soreide O. The survival benefit of resection in patients with advanced stomach cancer: the Norwegian multicenter experience. Norwegian Stomach Cancer Trial. World J Surg. 1989;13(5):617-21 discussion 21-2.

19. Ebinger SM, Warschkow R, Tarantino I, Schmied BM, Guller U, Schiesser M. Modest overall survival improvements from 1998 to 2009 in metastatic gastric cancer patients: a population-based SEER analysis. Gastric Cancer. 2016;19(3):723-34.

20. Warschkow R, Baechtold M, Leung K, Schmied BM, Nussbaum DP, Gloor B, et al. Selective survival advantage associated with primary tumor resection for metastatic gastric cancer in a Western population. Gastric Cancer. 2018;21(2):324-37.

21. Lulu DJ, Ochoa P. Carcinoma of the stomach. Int Surg. 1974;59(1):18-9.

22. Zacho A, Cederqvist C, Fischerman K. Surgical treatment of gastric malignancies: a twenty-year series comprising mainly far advanced and high-seated tumors. Ann Surg. 1974;179(1):94-101.

23. Zwaveling A. Palliative surgical treatment of gastric carcinoma, duration of survival in 217 cases. Arch Chir Neerl. 1976;28(1):512.

24. Nelson PG, Collier N. Carcinoma of the stomach: the need for a new approach. Aust N Z J Surg. 1982;52(4):358-62.

25. Yap P, Pantangco E, Yap A, Yap R. Surgical management of gastric carcinoma. Follow-up results in 465 consecutive cases. Am J Surg. 1982;143(3):284-7.

26. Choi TK, Koo J, Wong J, Ong GB. Survival after surgery for advanced carcinoma of the stomach other than the cardia. Am J Surg. 1982;143(6): 748-50.

27. Meijer S, De Bakker OJ, Hoitsma HF. Palliative resection in gastric cancer. J Surg Oncol. 1983;23(2):77-80.

28. Yan CJ, Brooks JR. Surgical management of gastric adenocarcinoma. Am J Surg. 1985;149(6):771-4.

29. Cunningham D, Hole D, Taggart DJ, Soukop M, Carter DC, McArdle CS. Evaluation of the prognostic factors in gastric cancer: the effect of chemotherapy on survival. Br J Surg. 1987;74(8): 715-20.

30. Bozzetti F, Bonfanti G, Audisio RA, Doci R, Dossena G, Gennari $\mathrm{L}$, et al. Prognosis of patients after palliative surgical procedures for carcinoma of the stomach. Surg Gynecol Obstet. 1987;164(2): $151-4$.

31. de Calan L, Portier G, Ozoux JP, Rivallain B, Perrier M, Brizon J. Carcinoma of the cardia and proximal third of the stomach. Results of surgical treatment in 91 consecutive patients. Am J Surg. 1988;155(3):481-5.

32. Butler JA, Dubrow TJ, Trezona T, Klassen M, Nejdl RJ. Total gastrectomy in the treatment of advanced gastric cancer. Am J Surg. 1989;158(6):602-4 discussion 4-5.

33. Carmalt HL, Gillett DJ, Hollinshead JW. Carcinoma of the stomach: a review with special reference to total gastrectomy. Aust N Z J Surg. 1990;60(10):759-63.

34. Habu H, Saito N, Sato Y, Takeshita K, Sunagawa M, Endo M. Results of surgery in patients with gastric cancer extending to the adjacent organs. Hepatogastroenterology. 1990;37(4):417-20.

35. Nakajima T, Nishi M, Kajitani T. Improvement in treatment results of gastric cancer with surgery and chemotherapy: experience of 9,700 cases in the Cancer Institute Hospital, Tokyo. Semin Surg Oncol. 1991;7(6):365-72.

36. Yonemura Y, Katayama K, Kamata T, Fushida S, Segawa M, Ooyama S, et al. Surgical treatment of advanced gastric cancer with metastasis in para-aortic lymph node. Int Surg. 1991;76(4): 222-5.

37. Monson JR, Donohue JH, McIlrath DC, Farnell MB, Ilstrup DM. Total gastrectomy for advanced cancer. A worthwhile palliative procedure. Cancer. 1991;68(9):1863-8.

38. Maehara Y, Moriguchi S, Orita H, Kakeji Y, Haraguchi M, Korenaga D, et al. Lower survival rate for patients with carcinoma 
of the stomach of Borrmann type IV after gastric resection. Surg Gynecol Obstet. 1992;175(1):13-6.

39. Maehara Y, Sakaguchi Y, Moriguchi S, Orita H, Korenaga D, Kohnoe S, et al. Signet ring cell carcinoma of the stomach. Cancer. 1992;69(7):1645-50.

40. Huguier M, Houry S, Lacaine F. Is the follow-up of patients operated on for gastric carcinoma of benefit to the patient? Hepatogastroenterology. 1992;39(1):14-6.

41. Maehara Y, Kakeji Y, Takahashi I, Okuyama T, Baba H, Anai H, et al. Noncurative resection for advanced gastric cancer. J Surg Oncol. 1992;51(4):221-5.

42. Baba H, Okuyama T, Hiroyuki O, Anai H, Korenaga D, Maehara Y, et al. Prognostic factors for noncurative gastric cancer: univariate and multivariate analyses. J Surg Oncol. 1992;51(2):104-8.

43. Geoghegan JG, Keane TE, Rosenberg IL, Dellipiani AW, Peel AL. Gastric cancer: the case for a more selective policy in surgical management. J R Coll Surg Edinb. 1993;38(4):208-12.

44. Ti TK. Surgical management of gastric cancer-a personal series of 160 cases. Ann Acad Med Singap. 1993;22(2):146-50.

45. Crookes PF, Incarbone R, Peters JH, Engle S, Bremner CG, DeMeester TR. A selective therapeutic approach to gastric cancer in a large public hospital. Am J Surg. 1995;170(6):602-5.

46. Chow LWC, Lim BH, Leung SYL, Branicki FJ, Gertsch P. Gastric carcinoma with synchronous liver metastases: palliative gastrectomy or not? ANZ J Surg. 1995;65(10):719-23.

47. Arak A, Lehtola J, Makela J, Tuominen H. Gastric cancer: surgical management and prognosis. Ann Chir Gynaecol. 1996;85(4):2938.

48. Saito A, Korenaga D, Sakaguchi Y, Ohno S, Ichiyoshi Y, Sugimachi K. Surgical treatment for gastric carcinomas with concomitant hepatic metastasis. Hepatogastroenterology. 1996;43(9): $560-4$.

49. Cenitagoya GF, Bergh CK, Klinger-Roitman J. A prospective study of gastric cancer. 'Real' 5-year survival rates and mortality rates in a country with high incidence. Dig Surg. 1998;15(4):31722.

50. Kikuchi S, Arai Y, Morise M, Kobayashi N, Tsukamoto H, Shimao H, et al. Gastric cancer with metastases to the distant peritoneum: a 20 -year surgical experience. Hepatogastroenterology. 1998;45(22):1183-8.

51. Sanchez-Bueno F, Garcia-Marcilla JA, Perez-Flores D, PerezAbad JM, Vicente R, Aranda F, et al. Prognostic factors in a series of 297 patients with gastric adenocarcinoma undergoing surgical resection. Br J Surg. 1998;85(2):255-60.

52. Piso P, Jähne J, Meyer HJ. Results of Palliative resections for gastric carcinoma. Oncol Res Treat. 1998;21(5):408-11.

53. Piso P, Bellin T, Aselmann H, Bektas H, Schlitt HJ, Klempnauer $\mathrm{J}$. Results of combined gastrectomy and pancreatic resection in patients with advanced primary gastric carcinoma. Dig Surg. 2002;19(4):281-5.

54. Lo SS, Kuo HS, Wu CW, Hsieh MC, Shyr YM, Wang HC, et al. Poorer prognosis in young patients with gastric cancer? Hepatogastroenterology. 1999;46(28):2690-3.

55. Doglietto GB, Pacelli F, Caprino P, Alfieri S, Carriero C, Malerba $\mathrm{M}$, et al. Palliative surgery for far-advanced gastric cancer: a retrospective study on 305 consecutive patients. Am Surg. 1999;65(4):352-5.

56. Llanos O, Guzman S, Pimentel F, Ibanez L, Duarte I. Results of surgical treatment of gastric cancer. Dig Surg. 1999;16(5):385-8.

57. Saidi F, Keshoofy M, Abbassi-Dezfuli A, Ahamadi ZH, Shadmehr MB. A new approach to the palliation of advanced proximal gastric cancer. J Am Coll Surg. 1999;189(3):259-68.

58. Doglietto GB, Pacelli F, Caprino P, Sgadari A, Crucitti F. Surgery: independent prognostic factor in curable and far advanced gastric cancer. World J Surg. 2000;24(4):459-64.
59. Ikeguchi M, Oka S, Gomyo Y, Tsujitani S, Maeta M, Kaibara N. Postoperative morbidity and mortality after gastrectomy for gastric carcinoma. Hepatogastroenterology. 2001;48(41):1517-20.

60. Hanazaki K, Sodeyama H, Mochizuki Y, Igarashi J, Yokoyama S, Sode $\mathrm{Y}$, et al. Palliative gastrectomy for advanced gastric cancer. Hepatogastroenterology. 2001;48(37):285-9.

61. Dhar DK, Kubota H, Tachibana M, Kinugasa S, Masunaga R, Shibakita M, et al. Prognosis of T4 gastric carcinoma patients: an appraisal of aggressive surgical treatment. J Surg Oncol. 2001;76(4):278-82.

62. Fujisaki S, Tomita R, Nezu T, Kimizuka K, Park E, Fukuzawa M. Prognostic studies on gastric cancer with concomitant liver metastases. Hepatogastroenterology. 2001;48(39):892-4.

63. Bonenkamp JJ, Sasako M, Hermans J, van de Velde CJ. Tumor load and surgical palliation in gastric cancer. Hepatogastroenterology. 2001;48(41):1219-21.

64. Liu KJ, Atten MJ, Donahue PE, Attar BM. Extended lymphadenectomy for gastric cancer: results in a teaching hospital. Am Surg. 2002;68(4):365-71 discussion 71-2.

65. Wang CS, Hsieh CC, Chao TC, Jan YY, Jeng LB, Hwang TL, et al. Resectable gastric cancer: operative mortality and survival analysis. Chang Gung Med J. 2002;25(4):216-27.

66. Collard J-M, Malaise J, Mabrut J-Y, Kestens P-J. Skeletonizing en-bloc gastrectomy for adenocarcinoma in Caucasian patients. Gastric Cancer. 2003;6(4):210-6.

67. Yoshikawa T, Kanari M, Tsuburaya A, Kobayashi O, Sairenji M, Motohashi H, et al. Should gastric cancer with peritoneal metastasis be treated surgically? Hepatogastroenterology. 2003;50(53): 1712-5.

68. Gill S, Shah A, Le N, Cook EF, Yoshida EM. Asian ethnicityrelated differences in gastric cancer presentation and outcome among patients treated at a Canadian Cancer Center. J Clin Oncol. 2003;21(11):2070-6.

69. Kobayashi A, Nakagohri T, Konishi M, Inoue K, Takahashi S, Itou M, et al. Aggressive surgical treatment for T4 gastric cancer. J Gastrointest Surg. 2004;8(4):464-70.

70. Moriwaki Y, Kunisaki C, Kobayashi S, Harada H, Imai S, Kasaoka C. Does the surgical stress associated with palliative resection for patients with incurable gastric cancer with distant metastasis shorten their survival? Hepatogastroenterology. 2004;51(57):872-5.

71. Kahlke V, Doniec JM, Küchler T, Kremer B, Schmid A, Bestmann B. Palliation of metastatic gastric cancer: impact of preoperative symptoms and the type of operation on survival and quality of life. World J Surg. 2004;28(4):369-75.

72. Zhang X-F. Surgical treatment and prognosis of gastric cancer in 2 613 patients. World J Gastroenterol. 2004;10(23):3405-8.

73. Gorbunov EA, Wechsler J, Stasek J, Tomin AS, Solodun LD. Significant prognostic factors in 283 patients after surgery for adenocarcinoma of the stomach. Scr Med. 2005;78(1):3-16.

74. Kunisaki C, Shimada H, Nomura M, Matsuda G, Otsuka Y, Ono $\mathrm{H}$, et al. Therapeutic strategy for scirrhous type gastric cancer. Hepatogastroenterology. 2005;52(61):314-8.

75. Saidi RF, ReMine SG, Dudrick PS, Hanna NN. Is there a role for palliative gastrectomy in patients with stage IV gastric cancer? World J Surg. 2005;30(1):21-7.

76. Alici S, Kaya S, Izmirli M, Tuncer I, Dogan E, Ozbek H, et al. Analysis of survival factors in patients with advanced-stage gastric adenocarcinoma. Med Sci Monit. 2006;12(5):CR221-9.

77. Samarasam I, Chandran BS, Sitaram V, Perakath B, Nair A, Mathew G. Palliative gastrectomy in advanced gastric cancer: is it worthwhile? ANZ J Surg. 2006;76(1-2):60-3.

78. Oñate-Ocaña LF, Méndez-Cruz G, Hernández-Ramos R, Becker M, Carrillo JF, Herrera-Goepfert R, et al. Experience of surgical morbidity after palliative surgery in patients with gastric carcinoma. Gastric Cancer. 2007;10(4):215-20. 
79. Nazli O, Yaman I, Tansug T, Isguder AS, Bozdag AD, Bolukbasi H. Palliative surgery for advanced stage (stage IV) gastric adenocarcinoma. Hepatogastroenterology. 2007;54(73):298-303.

80. Lim S, Muhs BE, Marcus SG, Newman E, Berman RS, Hiotis SP. Results following resection for stage IV gastric cancer; are better outcomes observed in selected patient subgroups? J Surg Oncol. 2007;95(2):118-22.

81. Lello E, Furnes B, Edna T-H. Short and long-term survival from gastric cancer. A population-based study from a county hospital during 25 years. Acta Oncol. 2007;46(3):308-15.

82. Mizutani S, Shioya T, Maejima K, Yoshino M, Komine O, Bou H, et al. Significance of gastrectomy as palliative surgery for gastric carcinoma with pyloric stenosis. J Nippon Med Sch. 2007;74(3): 241-5.

83. Nazli O, Derici H, Tansug T, Yaman I, Bozdag AD, Isguder AS, et al. Survival analysis after surgical treatment of gastric cancer: review of 121 cases. Hepatogastroenterology. 2007;54(74):625-9.

84. Kim DY, Joo JK, Park YK, Ryu SY, Kim YJ, Kim SK, et al. Is palliative resection necessary for gastric carcinoma patients? Langenbeck's Arch Surg. 2007;393(1):31-5.

85. Pacelli F. Four hundred consecutive total gastrectomies for gastric cancer. Arch Surg. 2008;143(8):769-75 discussion 775.

86. Du J, Li J, Li Y, Ji G, Yang Z, Gao Z, et al. Laparoscopicallyassisted palliative total gastrectomy in patients with stage IV or metastatic gastric cancer: is it worthwhile? Hepatogastroenterology. 2008;55(86-87):1908-12.

87. Lin SZ, Tong HF, You T, Yu YJ, Wu WJ, Chen C, et al. Palliative gastrectomy and chemotherapy for stage IV gastric cancer. J Cancer Res Clin Oncol. 2008;134(2):187-92.

88. Park SH, Kim JH, Park JM, Park SS, Kim SJ, Kim CS, et al. Value of nonpalliative resection as a therapeutic and pre-emptive operation for metastatic gastric cancer. World J Surg. 2009;33(2):30311.

89. Lupascu C, Andronic D, Ursulescu C, Vasiluta C, Raileanu G, Georgescu S, et al. Palliative gastrectomy in patients with stage IV gastric cancer-our recent experience. Chirurgia (Bucur). 2010;105(4):473-6.

90. Huang K-H, Wu C-W, Fang W-L, Chen J-H, Lo S-S, Wang R-F, et al. Palliative resection in noncurative gastric cancer patients. World J Surg. 2010;34(5):1015-21.

91. Hioki M, Gotohda N, Konishi M, Nakagohri T, Takahashi S, Kinoshita T. Predictive factors improving survival after gastrectomy in gastric cancer patients with peritoneal carcinomatosis. World J Surg. 2010;34(3):555-62.

92. Sah BK, Chen MM, Yan M, Zhu ZG. Reoperation for early postoperative complications after gastric cancer surgery in a Chinese hospital. World J Gastroenterol. 2010;16(1):98-103.

93. Ozer I, Bostanci EB, Koc U, Karaman K, Ercan M, Ulas M, et al. Surgical treatment for gastric cancer in Turkish patients over age 70: early postoperative results and risk factors for mortality. Langenbeck's Arch Surg. 2010;395(8):1101-6.

94. Li C, Yan M, Chen J, Xiang M, Zhu ZG, Yin HR, et al. Survival benefit of non-curative gastrectomy for gastric cancer patients with synchronous distant metastasis. J Gastrointest Surg. 2010;14(2):282-8

95. Xue Y-W, Wei Y-Z. The relationship of prognosis to surgery and pathologic characteristics of stage IV (M0) gastric cancer patients. Chin J Cancer. 2010;29(4):355-8.

96. Turanli S. The value of resection of primary tumor in gastric cancer patients with liver metastasis. Indian J Surg. 2010;72(3):2005 .

97. Schauer M, Peiper M, Theisen J, Knoefel W. Prognostic factors in patients with diffuse type gastric cancer (linitis plastica) after operative treatment. Eur J Med Res. 2011;16(1):29-33.

98. Al-Amawi T, Świder-Al-Amawi M, Halczak M, Wojtasik P, Kładny J. Advisability of palliative resections in incurable advanced gastric cancer. Pol J Surg. 2011;83(8):449-456. https://doi.org/10.2478/v10035-011-0070-0

99. Tanizawa Y, Bando E, Kawamura T, Tokunaga M, Kondo J, Taki $\mathrm{Y}$, et al. Influence of a positive proximal margin on oral intake in patients with palliative gastrectomy for far advanced gastric cancer. World J Surg. 2011;35(5):1030-4.

100. Zhang J-Z, Lu H-S, Huang C-M, Wu X-Y, Wang C, Guan G-X, et al. Outcome of palliative total gastrectomy for stage IV proximal gastric cancer. Am J Surg. 2011;202(1):91-6.

101. Izuishi K, Haba R, Kushida Y, Kadota K, Takebayashi R, Sano T, et al. S-1 and the treatment of gastric cancer with peritoneal dissemination. Exp Ther Med. 2011;2(5):985-90.

102. Lai K-K, Fang W-L, Wu C-W, Huang K-H, Chen J-H, Lo S-S, et al. Surgical impact on gastric cancer with locoregional invasion. World J Surg. 2011;35(11):2479-84.

103. Miki Y, Fujitani K, Hirao M, Kurokawa Y, Mano M, Tsujie M, et al. Significance of surgical treatment of liver metastases from gastric cancer. Anticancer Res. 2012;32(2):665-70.

104. Kokkola A, Louhimo J, Puolakkainen P. Does non-curative gastrectomy improve survival in patients with metastatic gastric cancer? J Surg Oncol. 2012;106(2):193-6.

105. Shim JH, Ko KJ, Yoo HM, Oh SI, Jeon DJ, Jeon HM, et al. Morbidity and mortality after non-curative gastrectomy for gastric cancer in elderly patients. J Surg Oncol. 2012;106(6):753-6.

106. Alonso-Larraga JO, Álvaro-Villegas JC, Sobrino-Cossio S, Hernández-Guerrero A, de-la Mora-Levy G, Figueroa-Barojas P. Self-expanding metal stents versus antrectomy for the palliative treatment of obstructive adenocarcinoma of the gastric antrum. Rev Esp Enferm Dig. 2012;104(4):185-9.

107. Tokunaga M, Terashima M, Tanizawa Y, Bando E, Kawamura T, Yasui $\mathrm{H}$, et al. Survival benefit of palliative gastrectomy in gastric cancer patients with peritoneal metastasis. World J Surg. 2012;36(11):2637-43.

108. Amaral L, Mendes J, Martins P, Bernardo L, Quintanilha R, Santos V, et al. Survival benefits of palliative gastric cancer resection - a regional center experience. Hepatogastroenterology. 2012;59(117):1651-6.

109. Naka T, Iwahashi M, Nakamori M, Nakamura M, Ojima T, Iida T, et al. The evaluation of surgical treatment for gastric cancer patients with noncurative resection. Langenbeck's Arch Surg. 2012;397(6):959-66.

110. Chang YR, Han DS, Kong SH, Lee HJ, Kim SH, Kim WH, et al. The value of palliative gastrectomy in gastric cancer with distant metastasis. Ann Surg Oncol. 2012;19(4):1231-9.

111. Kang L-Y, Mok K-T, Liu S-I, Tsai C-C, Wang B-W, Chen IS, et al. Intraoperative hyperthermic intraperitoneal chemotherapy as adjuvant chemotherapy for advanced gastric cancer patients with serosal invasion. J Chin Med Assoc. 2013;76(8):425-31.

112. Keränen I, Kylänpää L, Udd M, Louhimo J, Lepistö A, Halttunen $\mathrm{J}$, et al. Gastric outlet obstruction in gastric cancer: a comparison of three palliative methods. J Surg Oncol. 2013;108(8):537-41.

113. He M-m, Zhang D-s, Wang F, Wang Z-q, Luo H-y, Jin Y, et al. The role of non-curative surgery in incurable, asymptomatic advanced gastric cancer. PLoS ONE. 2013;8(12):e83921.

114. Ikeguchi M, Kader A, Takaya S, Fukumoto Y, Osaki T, Saito H, et al. Treatment of patients with stage IV gastric cancer. J Gastrointest Cancer. 2013;44(2):199-202.

115. Xia X, Li C, Yan M, Liu B, Yao X, Zhu Z. Who will benefit from noncurative resection in patients with gastric cancer with single peritoneal metastasis? Am Surg. 2014;80(2):124-30.

116. Kwon KJ, Shim KN, Song EM, Choi JY, Kim SE, Jung HK, et al. Clinicopathological characteristics and prognosis of signet ring cell carcinoma of the stomach. Gastric Cancer. 2014;17(1):43-53.

117. Zeeneldin AA, Ramadan H, El Gammal MM, Saber MM, Elgamal D, Sherisher MA. Gastric carcinoma at Tanta Cancer Center: a comparative retrospective clinico-pathological study of 
the elderly versus the non-elderly. J Egypt Natl Cancer Inst. 2014;26(3):127-37.

118. Zeng W-J, Hu W-Q, Wang L-W, Yan S-G, Li J-D, Zhao H-L, et al. Long term follow up and retrospective study on 533 gastric cancer cases. BMC Surg. 2014;14:29. https://doi.org/10.1186/ 1471-2482-14-29

119. Jeong O, Park YK, Choi WY, Ryu SY. Prognostic significance of non-curative gastrectomy for incurable gastric carcinoma. Ann Surg Oncol. 2014;21(8):2587-93.

120. Kim SW. The result of conversion surgery in gastric cancer patients with peritoneal seeding. J Gastric Cancer. 2014;14(4):26670.

121. da Costa WL Jr, Coimbra FJ, Ribeiro HS, Diniz AL, de Godoy $\mathrm{AL}$, de Farias IC, et al. Total gastrectomy for gastric cancer: an analysis of postoperative and long-term outcomes through time: results of 413 consecutive cases in a single cancer center. Ann Surg Oncol. 2015;22(3):750-7.

122. Matsumoto S, Takayama T, Wakatsuki K, Tanaka T, Migita K, Ito $\mathrm{M}$, et al. Palliative surgery for gastric cancer with gastric outlet obstruction or anemia due to tumor bleeding. Hepatogastroenterology. 2015;62(140):1041-6.

123. Yao G-L. Radical gastrectomy with hepatoarterial catheter implantation for late-stage gastric cancer. World J Gastroenterol. 2015;21(9):2754-8.

124. Yang K, Liu K, Zhang W-H, Lu Z-H, Chen X-Z, Chen X-L, et al. The value of palliative gastrectomy for gastric cancer patients with intraoperatively proven peritoneal seeding. Medicine. 2015;94(27):e1051.

125. Dong Y, Ma S, Yang S, Luo F, Wang Z, Guo F. Non-curative surgery for patients with gastric cancer with local peritoneal metastasis. Medicine. 2016;95(49):e5607.

126. Coimbra FJ, da Costa WL Jr, Ribeiro HS, Diniz AL, de Godoy AL, de Farias IC, et al. Noncurative resection for gastric cancer patients: who could benefit?: determining prognostic factors for patient selection. Ann Surg Oncol. 2016;23(4):1212-9.

127. Chiu C-F, Yang H-R, Yang M-D, Jeng L-B, Yang T-Y, Sargeant $\mathrm{AM}$, et al. Palliative gastrectomy prolongs survival of metastatic gastric cancer patients with normal preoperative CEA or CA19-9 values: a retrospective cohort study. gastroenterology research and practice. 2016;2016:6846027. https://doi.org/10.1155/2016/ 6846027

128. Musri FY, Mutlu H, Karaagac M, Eryilmaz MK, Gunduz S, Artac M. Primary tumor resection and survival in patients with stage IV gastric cancer. J Gastric Cancer. 2016;16(2):78-84.

129. Ikeguchi M, Miyatani K, Takaya S, Matsunaga T, Fukumoto Y, Osaki $\mathrm{T}$, et al. Role of surgery in the management for gastric cancer with synchronous distant metastases. Indian J Surg Oncol. 2016;7(1):32-6.

130. Nie RC, Chen S, Yuan SQ, Chen XJ, Chen YM, Zhu BY, et al. Significant role of palliative gastrectomy in selective gastric cancer patients with peritoneal dissemination: a propensity score matching analysis. Ann Surg Oncol. 2016;23(12):3956-63.

131. Tokunaga M, Makuuchi R, Miki Y, Tanizawa Y, Bando E, Kawamura T, et al. Surgical and survival outcome following truly palliative gastrectomy in patients with incurable gastric cancer. World J Surg. 2016;40(5):1172-7.

132. Fujitani K, Ando M, Sakamaki K, Terashima M, Kawabata R, Ito $\mathrm{Y}$, et al. Multicentre observational study of quality of life after surgical palliation of malignant gastric outlet obstruction for gastric cancer. BJS Open. 2017;1(6):165-74.

133. Hsu J-T, Liao J-A, Chuang H-C, Chen T-D, Chen T-H, Kuo C-J, et al. Palliative gastrectomy is beneficial in selected cases of metastatic gastric cancer. BMC Palliat Care. 2017;16(1):19. https:// doi.org/10.1186/s12904-017-0192-1.

134. Fornaro L, Fanotto V, Musettini G, Uccello M, Rimassa L, Vivaldi C, et al. Selecting patients for gastrectomy in metastatic esophago-gastric cancer: clinics and pathology are not enough. Future Oncol. 2017;13(25):2265-75.

135. Yuan S-Q, Nie R-C, Chen S, Chen X-J, Chen Y-M, Xu L-P, et al. Selective gastric cancer patients with peritoneal seeding benefit from gastrectomy after palliative chemotherapy: a propensity score matching analysis. J Cancer. 2017;8(12):2231-7.

136. Fukuchi M, Mochiki E, Ishiguro T, Kumagai Y, Ishibashi K, Ishida $\mathrm{H}$. Prognostic significance of conversion surgery following first- or second-line chemotherapy for unresectable gastric cancer. Anticancer Res. 2018;38(11):6473-8.

137. Picado O, Dygert L, Macedo FI, Franceschi D, Sleeman D, Livingstone AS, et al. The role of surgical resection for stage iv gastric cancer with synchronous hepatic metastasis. J Surg Res. 2018:232:422-9.

138. Yuan SQ, Nie RC, Chen YM, Qiu HB, Li XP, Chen XJ, et al. Glasgow Prognostic Score is superior to ECOG PS as a prognostic factor in patients with gastric cancer with peritoneal seeding. Oncol Lett. 2018;15(4):4193-4200. https://doi.org/10.3892/ol. 2018.7826.

139. Yang LP, Wang ZX, He MM, Jin Y, Ren C, Wang ZQ, et al. The survival benefit of palliative gastrectomy and/or metastasectomy in gastric cancer patients with synchronous metastasis: a population-based study using propensity score matching and coarsened exact matching. J Cancer. 2019;10(3):602-10.

140. Omori H, Tanizawa Y, Makuuchi R, Irino T, Bando E, Kawamura $\mathrm{T}$, et al. Role of palliative resection in patients with incurable advanced gastric cancer who are unfit for chemotherapy. World J Surg. 2019;43(2):571-9.

141. Matsubara D, Konishi H, Kubota T, Kosuga T, Shoda K, Shiozaki A, et al. Comparison of Clinical Outcomes of Gastrojejunal Bypass and Gastrectomy in Patients With Metastatic Gastric Cancer. Anticancer Res. 2019;39(5):2545-51.

142. Smyth EC, Wotherspoon A, Peckitt C, Gonzalez D, HulkkiWilson S, Eltahir Z, et al. mismatch repair deficiency, microsatellite instability, and survival: an exploratory analysis of the Medical Research Council Adjuvant Gastric Infusional Chemotherapy (MAGIC) Trial. JAMA Oncol. 2017;3(9):1197203.

143. Cancer Genome Atlas Research N. Comprehensive molecular characterization of gastric adenocarcinoma. Nature. 2014;513(7517):202-9.

144. Wu CW, Hsiung CA, Lo SS, Hsieh MC, Chen JH, Li AF, et al. Nodal dissection for patients with gastric cancer: a randomised controlled trial. Lancet Oncol. 2006;7(4):309-15.

145. Songun I, Putter H, Kranenbarg EM, Sasako M, van de Velde CJ. Surgical treatment of gastric cancer: 15-year follow-up results of the randomised nationwide Dutch D1D2 trial. Lancet Oncol. 2010;11(5):439-49.

146. Pacelli F, Cusumano G, Rosa F, Marrelli D, Dicosmo M, Cipollari $\mathrm{C}$, et al. Multivisceral resection for locally advanced gastric cancer: an Italian multicenter observational study. JAMA Surg. 2013;148(4):353-60.

147. Tran TB, Worhunsky DJ, Norton JA, Squires MH 3rd, Jin LX, Spolverato G, et al. Multivisceral resection for gastric cancer: results from the US gastric cancer collaborative. Ann Surg Oncol. 2015;22(Suppl 3):S840-7.

148. Mita K, Ito H, Katsube T, Tsuboi A, Yamazaki N, Asakawa H, et al. Prognostic factors affecting survival after multivisceral resection in patients with clinical T4b gastric cancer. J Gastrointest Surg. 2017;21(12):1993-9.

149. Kanas GP, Taylor A, Primrose JN, Langeberg WJ, Kelsh MA, Mowat FS, et al. Survival after liver resection in metastatic colorectal cancer: review and meta-analysis of prognostic factors. Clin Epidemiol. 2012;4:283-301. 
150. Liao YY, Peng NF, Long D, Yu PC, Zhang S, Zhong JH, et al. Hepatectomy for liver metastases from gastric cancer: a systematic review. BMC Surg. 2017;17(1):14.

151. Shirasu H, Tsushima T, Kawahira M, Kawai S, Kawakami T, Kito $\mathrm{Y}$, et al. Role of hepatectomy in gastric cancer with multiple liverlimited metastases. Gastric Cancer. 2018;21(2):338-44.

152. Gill RS, Al-Adra DP, Nagendran J, Campbell S, Shi X, Haase E, et al. Treatment of gastric cancer with peritoneal carcinomatosis by cytoreductive surgery and HIPEC: a systematic review of survival, mortality, and morbidity. J Surg Oncol. 2011;104(6):692-8.

153. Boerner T, Graichen A, Jeiter T, Zemann F, Renner P, Marz L, et al. CRS-HIPEC prolongs survival but is not curative for patients with peritoneal carcinomatosis of gastric cancer. Ann Sug Oncol. 2016;23(12):3972-7.

154. Nadiradze G, Giger-Pabst U, Zieren J, Strumberg D, Solass W, Reymond MA. Pressurized intraperitoneal aerosol chemotherapy (PIPAC) with low-dose cisplatin and doxorubicin in gastric peritoneal metastasis. J Gastrointest Surg. 2016;20(2):367-73.

155. Al-Batran SE, Homann N, Pauligk C, Goetze TO, Meiler J, Kasper S, et al. Perioperative chemotherapy with fluorouracil plus leucovorin, oxaliplatin, and docetaxel versus fluorouracil or capecitabine plus cisplatin and epirubicin for locally advanced, resectable gastric or gastro-oesophageal junction adenocarcinoma (FLOT4): a randomised, phase $2 / 3$ trial. Lancet. 2019;393(10184):1948-57.

156. Bang YJ, Van Cutsem E, Feyereislova A, Chung HC, Shen L, Sawaki A, et al. Trastuzumab in combination with chemotherapy versus chemotherapy alone for treatment of HER2-positive advanced gastric or gastro-oesophageal junction cancer (ToGA): a phase 3, open-label, randomised controlled trial. Lancet. 2010;376(9742):687-97.

157. Hofheinz R. Perioperative trastuzumab and pertuzumab in combination with FLOT versus FLOT alone for HER2 positive resectable esophagogastric adenocarcinoma: Petrarca-A phase II trial of the German AIO. 2017;TPS4133-TPS4133. 2017; Journal of Clinical Oncology. https://doi.org/10.1200/JCO.2017.35.15 suppl.TPS4133.

158. Al-Batran SEea. Perioperative atezolizumab in combination with FLOT versus FLOT alone in patients with resectable esophagogastric adenocarcinoma: DANTE, a randomized, openlabel phase II trial of the German Gastric Group of the AIO and the SAKK. 2019. Journal of Clinical Oncology. https://doi.org/10. 1200/JCO.2019.37.15_suppl.TPS4142.

159. Muro K, Chung HC, Shankaran V, Geva R, Catenacci D, Gupta S, et al. Pembrolizumab for patients with PD-L1-positive advanced gastric cancer (KEYNOTE-012): a multicentre, open-label, phase 1b trial. Lancet Oncol. 2016;17(6):717-26.

160. Janjigian YYea. Nivolumab \pm ipilimumab in pts with advanced $(\mathrm{adv}) /$ metastatic chemotherapy-refractory $(\mathrm{CTx}-\mathrm{R})$ gastric $(\mathrm{G})$, esophageal (E), or gastroesophageal junction (GEJ) cancer: CheckMate 032 study. Journal of Clinical Oncology 2017;35: 15_suppl, 4014-4014.

Publisher's Note Springer Nature remains neutral with regard to jurisdictional claims in published maps and institutional affiliations. 